\title{
Spontaneous Intracranial Hypotension Complicated by Subdural Effusions Treated by Surgical Relief of Cranial Venous Outflow Obstruction
}

\author{
J Nicholas Higgins ${ }^{1}$ Patrick R. Axon ${ }^{2}$ Robert Macfarlane ${ }^{3}$ \\ ${ }^{1}$ Department of Radiology, Addenbrooke's Hospital, Cambridge, \\ United Kingdom \\ ${ }^{2}$ Cambridge Skull Base Unit, Addenbrooke's Hospital, Cambridge, \\ United Kingdom \\ Address for correspondence J. Nicholas Higgins, MA, FRCP, FRCR, \\ Department of Radiology, Addenbrooke's Hospital, Hills Road, \\ Cambridge CB2 0QQ, United Kingdom \\ (e-mail: nick.higgins@addenbrookes.nhs.uk).
}

3 Department of Neurosurgery, Addenbrooke's Hospital, Cambridge, United Kingdom

J Neurol Surg Rep 2020;81:e59-e65.

\author{
Abstract \\ Keywords \\ - Spontaneous \\ intracranial \\ hypotension \\ - cerebrospinal fluid \\ leak \\ - idiopathic intracranial \\ hypertension \\ - cranial venous \\ outflow obstruction \\ - jugular stenosis \\ - jugular venoplasty \\ - styloidectomy \\ - C1 transverse process \\ resection
}

Spontaneous intracranial hypotension describes the clinical syndrome brought on by a cerebrospinal fluid (CSF) leak. Orthostatic headache is the key symptom, but others include nausea, vomiting, and dizziness, as well as cognitive and mood disturbance. In severe cases, the brain slumps inside the cranium and subdural collections develop to replace lost CSF volume. Initial treatment is by bed rest, but when conservative measures fail, attention is focused on finding and plugging the leak, although this can be very difficult and some patients remain bedbound for months or years. Recently, we have proposed an alternative approach in which obstruction to cranial venous outflow would be regarded as the driving force behind a chronic elevation of CSF pressure, which eventually causes dural rupture. Instead of focusing on the site of rupture, therefore, investigation and treatment can be directed at locating and relieving the obstructing venous lesion, allowing intracranial pressure to fall, and the dural defect to heal. The case we describe illustrates this idea. Moreover, since there was a graded clinical response to successive interventions relieving venous obstruction, and eventual complete resolution, it also provides an opportunity to consider particular symptoms in relation to cerebral venous insufficiency in its own right.

\section{Introduction}

Spontaneous intracranial hypotension describes the clinical syndrome brought on by a cerebrospinal fluid (CSF) leak. Headache is the dominant symptom, usually exacerbated in the upright position and relieved by lying flat, thought to be caused by distortion of pain-sensitive intracranial structures in the presence of CSF hypovolemia. Other symptoms, for example, mood disturbance, nausea, vomiting, and dizziness are more difficult to understand. The syndrome is perceived as rare but is probably under-reported. ${ }^{1,2}$

Most cases resolve with conservative management, mainly bed rest. Some require more active measures, essentially epidural blood patching. In rare instances, surgery may be indicated to repair a defect in the dural membrane. In very rare instances, symptoms are resistant to all treatments and patients are confined to bed for months or years. ${ }^{1,3,4}$ received

July 10,2020

accepted

October 28, 2020
DOI https://doi.org/

10.1055/s-0040-1722268. ISSN 2193-6358.

\footnotetext{
(C) 2020. The Author(s).

This is an open access article published by Thieme under the terms of the Creative Commons Attribution-NonDerivative-NonCommercial-License, permitting copying and reproduction so long as the original work is given appropriate credit. Contents may not be used for commercial purposes, or adapted, remixed, transformed or built upon. (https://creativecommons.org/ licenses/by-nc-nd/4.0/) Georg Thieme Verlag KG, Rüdigerstraße 14, 70469 Stuttgart, Germany
} 
The presence of a CSF leak is inferred from the clinical syndrome, supported by typical radiological findings. The leak itself, however, is often difficult or impossible to localize making it difficult to target surgical repair in cases that do not respond to more conservative measures. ${ }^{1,3-5}$

In recent years, it has been recognized that idiopathic intracranial hypertension (IIH) can present with a CSF leak and, equally, that many cases of spontaneous intracranial hypotension have $\mathrm{IIH}$ as the underlying cause. ${ }^{6,7}$ In this scenario, the defect in the dura that gives origin to the leak is the product of chronically raised intracranial pressure. ${ }^{8}$ This invites the notion that therapy normally used to reduce intracranial pressure (acetazolamide, ventriculo-peritoneal shunting) might contribute toward a lasting result from dural repair. $^{9}$

In the event, the most intractable cases of IIH are usually treated by CSF diversion anyway, but this is an intervention that seems counterintuitive in a patient who already has a CSF leak. With the advent of venous sinus stenting, however, there may be opportunity to reduce background intracranial hypertension without puncturing the dura, ${ }^{10}$ although uncertainty over whether this technique addresses primary or secondary venous sinus narrowings might have a bearing on the likelihood of success. ${ }^{11}$

Recently, we have proposed an alternative approach to CSF leaks in which intracranial venous hypertension from extracranial obstruction to cerebral venous outflow might be regarded as the driving force behind the initial elevation of CSF pressure which causes the dural rupture. ${ }^{12}$ Instead of focusing on the site of rupture, therefore, investigation and treatment could be directed at locating and relieving the obstructing venous lesion, allowing intracranial venous and CSF pressures to fall and the dural defect to heal. ${ }^{12,13}$ The case we describe illustrates this idea in clinical practice. Moreover, since there was more than one intervention, it also provides an opportunity to consider particular symptoms in relation to cerebral venous insufficiency in its own right.

\section{Case Report}

\section{History and Examination}

A 56-year-old male, previously fit and well and who worked as a data analyst, was referred with a 6-month history of headaches. These had begun suddenly with a "pop" inside his head when he had bent down to tie his shoelaces and at first manifested as sharp pains related to head movement. Gradually, however, they had become more persistent, severe, and unmistakably orthostatic. Later still his condition appeared to settle into a pattern, whereby unusual exertion produced a substantial symptomatic deterioration followed by a partial recovery over several weeks. As his cognition and memory became impaired, he had to stop work. Eventually, he was confined to bed, most of the time spent asleep. Physical examination was normal.

\section{Investigations}

Two months into his illness cranial magnetic resonance imaging (MRI) revealed symmetrical bilateral subdural col- lections over both cerebral hemispheres ( - Fig. 1A and $\mathbf{D}$ ). No specific treatment was prescribed, and at first, symptoms and imaging appeared stable. By 2 months, however, further MRI showed progression of the subdural collections and development of brain slump (-Fig. 1B and E). He was diagnosed with spontaneous intracranial hypotension.

Spinal MRI was unremarkable with no clue as to the site of any CSF leak. Further investigations, therefore, were directed at establishing the presence or otherwise of cranial venous outflow compromise.

The computed tomographic (CT) venography showed mildly dilated venous sinuses consistent with intracranial hypotension. There was also marked narrowing of both jugular veins between the styloid processes and lateral masses of the $\mathrm{C} 1$ vertebra ( $\mathbf{- F i g}$. 2A-C). Catheter cerebral venography, under local anesthesia, revealed mild intracranial venous hypertension-sagittal sinus pressure $20 \mathrm{~cm} \mathrm{H}_{2} \mathrm{O}$ (right atrial pressure $10 \mathrm{~cm} \mathrm{H}_{2} \mathrm{O}$ ) with $5 \mathrm{~cm} \mathrm{H}_{2} \mathrm{O}$ gradients across the jugular venous narrowings on each side (-Fig. $\mathbf{3}$ ). These narrowings were dilated to $8 \mathrm{~mm}$ with a balloon in the same session; this having no appreciable effect on the radiological appearances. However, his postural headache was unequivocally improved over the next 12 hours.

Therefore, he was diagnosed with bilateral jugular venous obstruction and referred for left styloidectomy and C1 transverse process resection as a preliminary to jugular stenting.

\section{Left Styloidectomy and C1 Transverse Process Resection}

Prior to the procedure, axial CT images were used to decide the extent of transverse process resection required to free the jugular vein from posterior compression, bearing in mind limitations imposed by the position of the vertebral artery as it passes through the transverse foramen ( $\mathbf{- F i g . ~ 2 B ) . ~ R e f o r - ~}$ matted images or trigonometrical calculations can be used to calculate the length of styloid that should be removed to achieve adequate anterior decompression.

The procedure was performed under general anesthesia with continuous intraoperative facial nerve monitoring. The patient was laid supine with the head slightly extended and turned away to the contralateral side. A postauricular incision was extended forward in front of the mastoid tip and then inferiorly into the neck avoiding the path of the marginal mandibular branch of the facial nerve. The anterior border of the sternocleidomastoid muscle was dissected free up to, and in front of, the mastoid tip. Further dissection medially through the deep cervical fascia toward the carotid sheath enabled identification of the posterior belly of the digastric. Palpation of the inferior wound identified the bony transverse process of the $\mathrm{C} 1$ vertebra and further dissection superoanteromedially, anterior to the posterior belly of the digastric, identified the body of the styloid process. The posterior belly of the digastric was drawn anteriorly and dissection continued posterior to the muscle until the prevertebral muscles were identified overlying the transverse process. Care was taken not to injure the internal jugular vein, which occasionally can be draped over these prevertebral muscles. 


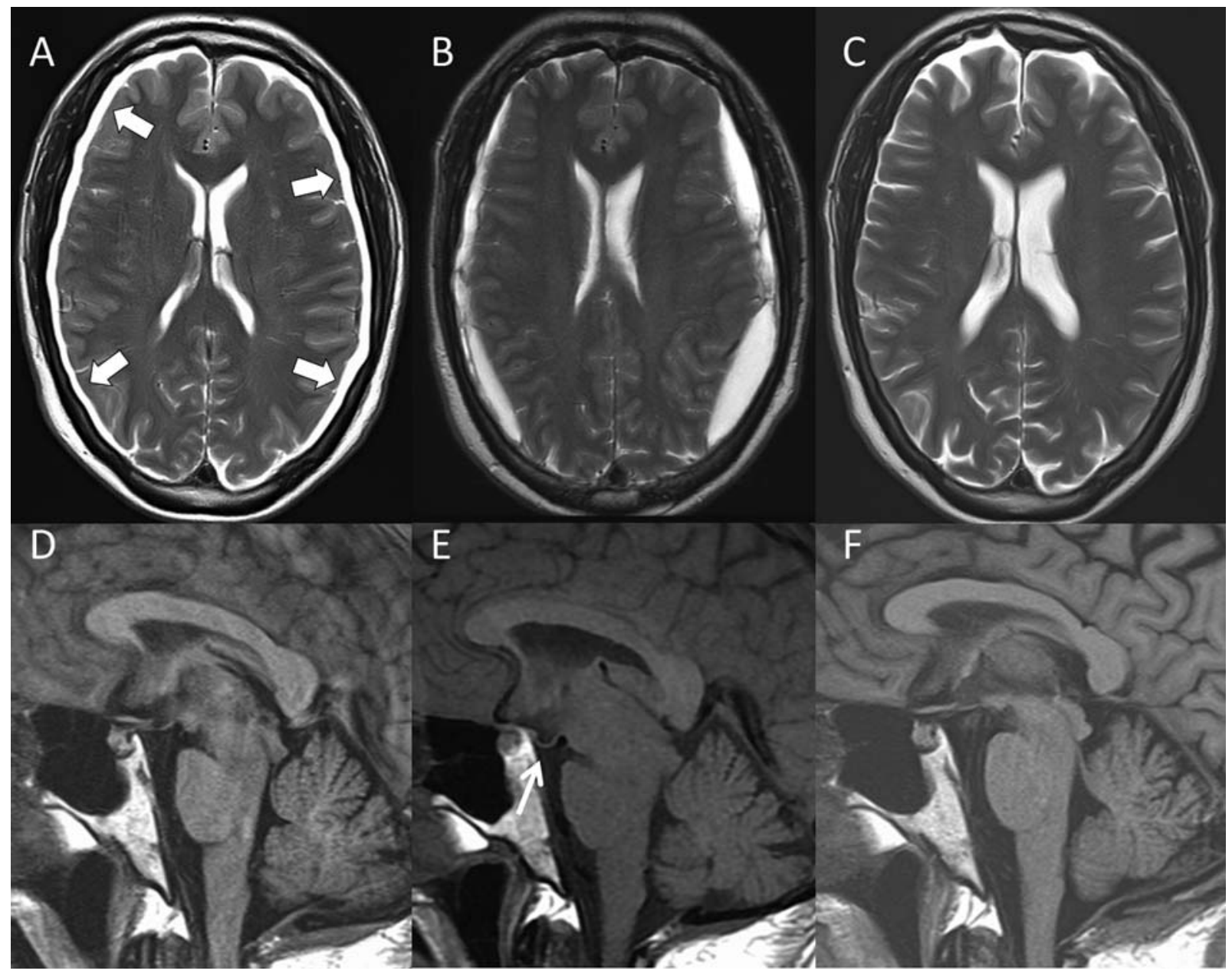

Fig. 1 (A) An axial T2 magnetic resonance imaging scan undertaken at presentation shows bilateral subdural effusions (block arrows), while the midline sagittal T1 image (D) shows little appreciable distortion of the brain stem. (B) Total 2 months later, the effusions are larger and there is evidence of brain slumping on the sagittal image $(E)$ with inferior depression of the floor of the third ventricle (arrow) and distortion of the midbrain and pons. (C) Total 4 months after first surgery effusions have resolved and normal brain anatomy is restored.

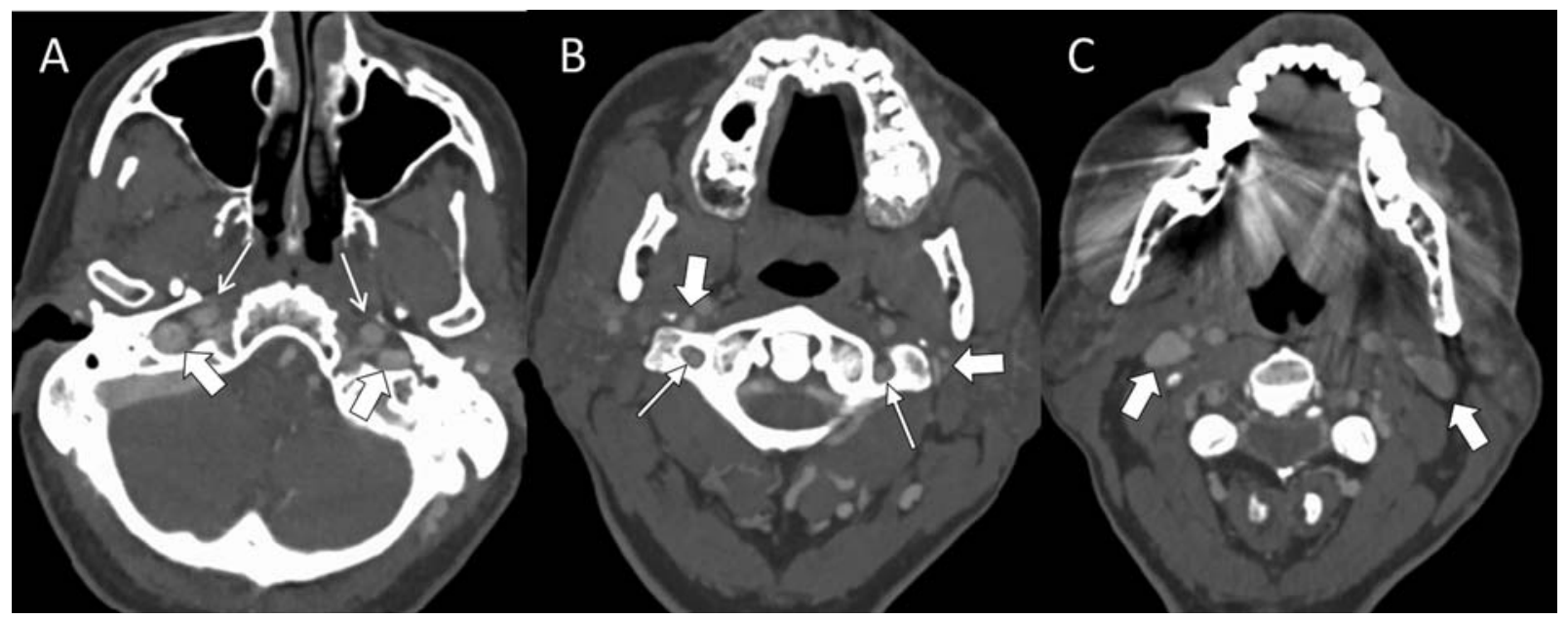

Fig. 2 (A) Axial computed tomography images through the skull base following intravenous contrast showing the jugular veins (block arrows) at exit from the cranium. The carotid arteries (thin arrows) lie just in front. (B) Axial cuts through the C1 vertebra show marked narrowing of the right internal jugular vein in front of the transverse process of $\mathrm{C} 1$ (block arrow) and of the left (block arrow) as it passes around the $\mathrm{C} 1$ transverse process more laterally. (Thin block arrow = vertebral artery in C1 transverse foramen). (C) A little more inferiorly and the jugular veins appear normal again. 


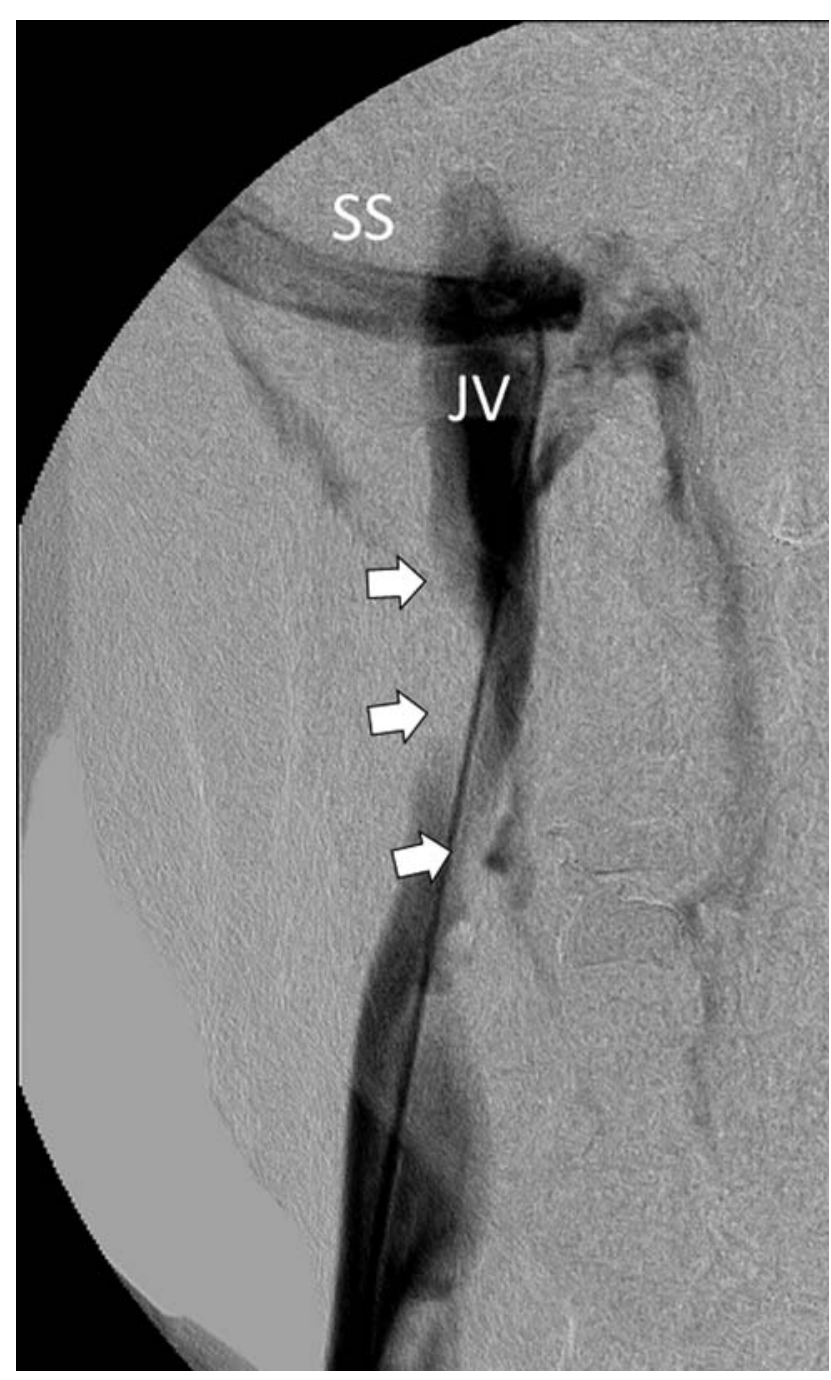

Fig. 3 Catheter venogram (frontal view). Radiographic contrast media, injected through a small catheter (thin black line on image), outlines the lower right sigmoid sinus, running into the right jugular vein. Block arrows show the impression on the vein caused by the styloid process in front and the $\mathrm{C} 1$ transverse process behind, and the consequent venous narrowing.

The prevertebral muscles were divided by sharp incision onto the bony transverse process, and the periosteum gently stripped from its tip. Malleable retractors were helpful in this regard. A 2-mm course cut diamond burr was used to gently create a hole that was then widened to enter the cancellous bone. This bone was easily drilled, thus gradually widening the aperture and keeping within the periosteal pocket, bearing in mind the anatomy in relation to the vertebral artery identified on prior CT.

Attention was then turned to the styloid. Blunt dissection toward the base of the styloid process above the inferior extent of the mastoid tip enabled an approximation of its origin. Two small malleable retractors were inserted in front and behind the styloid process, so giving secure anchorage to hold the soft tissue from its surface. A 2-mm course cut diamond burr was used gently to create a hole that was then widened in an anteroposterior direction to drill across its diameter. Bone was removed until its medial extent was egg shelled. At this point, the whole of the styloid process became mobile. A House Bone Curette was used to draw the base of the styloid process laterally until it could be safely held using a curved Spencer Wells forceps. An ophthalmic microsurgical blade was then used to gently strip the muscle attachments from its surface in an inferior direction while drawing the styloid superolaterally. The stylohyoid ligament was divided using scissors and the styloid process removed. At this point, the excised styloid measured $14 \mathrm{~mm}$ and compared with its preoperative length on CT imaging $(19 \mathrm{~mm})$ as described above. About $3 \mathrm{~mL}$ of residual styloid was still attached to the skull base after taking into account the 2-mm drill diameter. Malleable retractors were again used to hold soft tissue away from the styloid remnant, and this was drilled away to its base. Hemostasis was confirmed and a suction drain inserted. The wound was closed in layers.

He was nonspecifically unwell for 2 or 3 weeks following surgery, describing liquid sloshing around in his head with movement but gradually his headaches improved and within a month he was back at work. Follow-up MRI showed resolution of the subdural collections and restoration of normal brain anatomy (-Fig. 1C and F). The CT venogram showed expansion of the left jugular vein into the space created by removal of the styloid and $\mathrm{C} 1$ transverse process ( $\mathbf{F i g . 4 B}$ ), although there was some residual venous narrowing just below the skull base. The right internal jugular vein remained narrowed at the $\mathrm{C} 1$ level as before.

\section{Further Progress, Right Styloidectomy, and C1 Transverse Process Resection}

He remained quite fatigued and still had headaches precipitated by physical or mental exertion, although these were less severe than previously, there was no longer any postural component to them, and they were more quickly relieved by rest. He still had some impairment of memory and concentration which was affecting his work.

To test whether residual jugular venous narrowing was responsible for persistent symptoms, and with a view to stenting, he had repeat left jugular venoplasty after which his head felt better for a few hours. Anxious to avoid a jugular stent, however, he opted for surgical decompression of the opposite (right) jugular vein instead. Total 10 months after his first surgery, therefore, he had his second resection of the right transverse process of $\mathrm{C} 1$ and $18-\mathrm{mm}$ styloidectomy in a similar procedure to that described above.

Within a few weeks lethargy, headache, cognitive impairment, and all residual symptoms had resolved. He had no complaint of memory dysfunction or difficulty concentrating. He was able to work at full capacity. There has been no deterioration in 18 months of follow-up. The CT venogram confirmed good expansion of the right internal jugular vein at the site of surgery (-Fig. $\mathbf{4 C}$ ).

\section{Discussion}

The key lesion in spontaneous intracranial hypotension has always been regarded as the CSF leak. ${ }^{1,2}$ Beyond unspecified trauma, however, the reason a CSF leak should develop in the first place has not been explained except perhaps in the case 


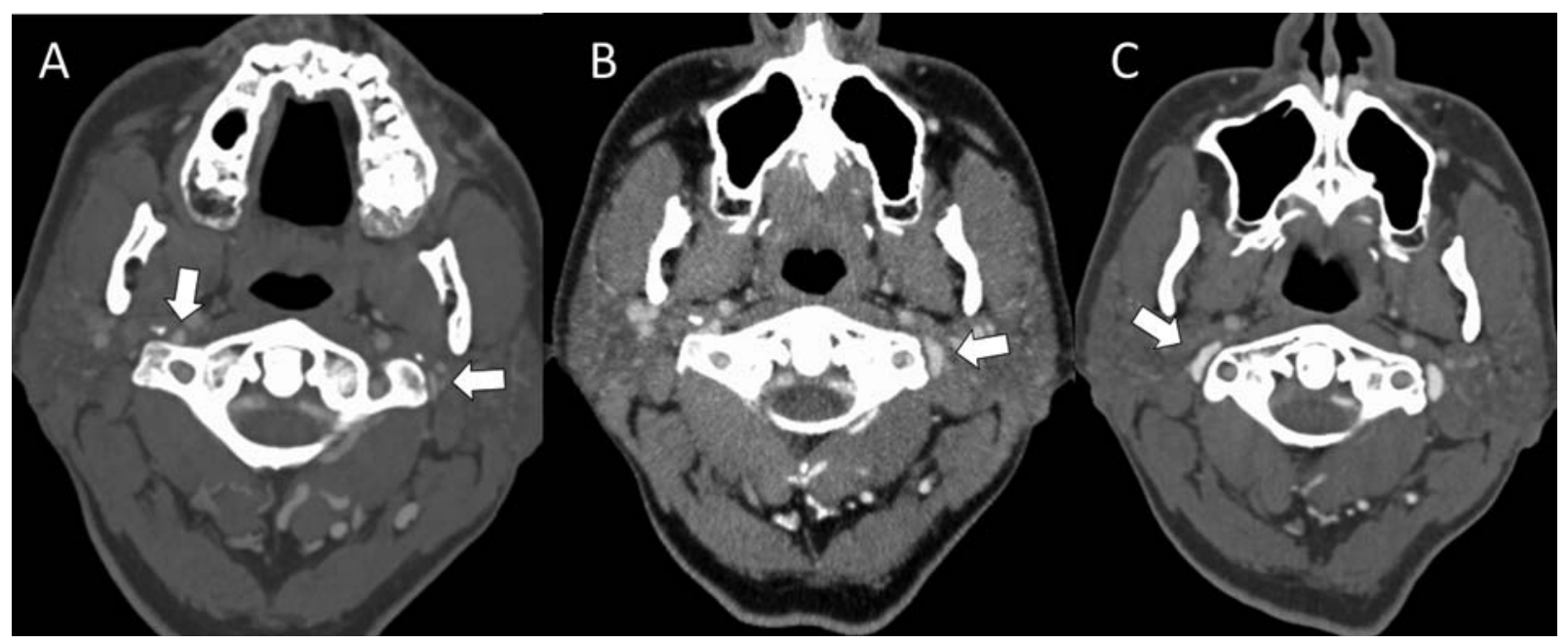

Fig. 4 Axial computed tomography scans following intravenous contrast through the $C 1$ vertebra. (A) Baseline scan showing bilateral jugular narrowing (block arrows). (B) There is expansion of the jugular vein on the left side, following left-side surgical resections (block arrow) and (C) on the right side (block arrow), following right-side surgical resections.

of Ehlers-Danlos syndrome, where a structural weakness in the dural membrane might make it especially prone to injury. ${ }^{1}$ Even where there is no evidence of a connective tissue disorder, however, the trauma evoked to have caused such an injury is often so mild (coughing or sneezing) as to raise questions as to why the condition is not seen more frequently.

So, is there some other underlying problem in patients with CSF leaks? Regardless of the level of trauma required to produce a dural tear and the strength of the dural membrane to resist it, a CSF leak has to be driven by a pressure gradient. Could these patients, therefore, have abnormally high background CSF pressures? IIH, for example in which CSF pressure is raised, can present with a CSF leak and many patients with the condition experience CSF leaks during the course of their illness. ${ }^{1,6-9}$ At the same time, some cases of spontaneous intracranial hypotension appear to have CSF pressures in the normal range, ${ }^{1,6}$ an observation which can only be explained if there is some other force elevating intracranial pressure in the first place. ${ }^{12}$

That cranial venous outflow obstruction can cause raised intracranial pressure is undisputed. Both superior vena cava obstruction and cerebral venous sinus thrombosis, for example, are well known causes of raised intracranial pressure; the latter sometimes producing a clinical syndrome indistinguishable from $\mathrm{IIH} .{ }^{14}$ If raised CSF pressure encourages the development of a CSF leak, therefore, there is no reason why sometimes cranial venous outflow obstruction might not be underlying cause.

In the case, we describe CT venography showed focal narrowing of the jugular veins where they run between the styloid processes and the lateral masses of the $\mathrm{C} 1$ vertebra. The question was whether these narrowings could be responsible for his clinical syndrome. In pursuit of this, catheter venography confirmed that they were associated with pressure gradients and a trial of jugular venoplasty produced a temporary symptomatic improvement. None of these findings or maneuvers are in routine use in this clinical situation. However, they have been described in relation to $\mathrm{IIH}^{15-17}$ and here formed the basis for a diagnosis of cranial venous outflow obstruction.

The treatment he received involved operative removal of bone anterior (the styloid process) and medial (the transverse process of $\mathrm{C} 1$ ) to the left jugular vein. This represents a refinement of the combined surgical and endovascular approach to this problem described previously, ${ }^{18,19}$ in which compressive forces on the jugular vein are minimized hoping to secure long-term survival of a subsequent stent or avoidance of a stent altogether. The left side was chosen because, in our view, the lateral position of jugular vein relative to the $\mathrm{C} 1$ transverse process ( $\mathbf{- F i g . ~ 2 B}$ ) predicted a more satisfactory technical result. Uncertain was whether a stent would be required or whether both sides would need to be treated to achieve a clinical benefit.

In the event, the first surgical decompression allowed only limited expansion of the left jugular vein, yet still was followed by resolution of the overt clinical syndrome and restoration of normal intracranial anatomy. Subtle residual symptoms persisted, however, in particular cognitive and memory disturbance, which interfered with the intellectual demands of his employment. These resolved completely after the second surgical decompression, which was more successful in relieving venous obstruction.

This raises several issues. In the first place, it reinforces the notion that cranial venous outflow obstruction can be the driving force behind a CSF leak. ${ }^{12,13}$ Second, his response to the second surgical procedure, lends weight to the idea that obstruction to cranial venous outflow can be symptomatic in its own right, before any leak develops. Spontaneous intracranial hypotension therefore could be regarded as a complication of a syndrome - cranial venous outflow obstruction-that is subclinical, or unrecognized, until the dura ruptures; the symptoms he experienced between his two surgical procedures-headache, fatigue, cognitive, and memory impairment -giving an indication of its likely clinical features. ${ }^{17,20}$ 
With failure of conservative measures, the treatment of spontaneous intracranial hypotension is usually directed at plugging the leak. In most cases, this means epidural blood patching which is usually undertaken with scant knowledge of where the leak is located because the leak is often invisible to radiological imaging. Nevertheless, most cases respond, if not to the first patch, then to a second. ${ }^{1,2,4}$ Intractable cases may be investigated with intrathecal gadolinium MRI, ${ }^{21,22}$ digital subtraction myelography, ${ }^{23,24}$ or dynamic CT myelography, ${ }^{25}$ hoping to target therapeutic efforts more precisely, but these tests may still be negative in the face of a florid clinical syndrome. Moreover, even when the site of leakage seems to have been identified, efforts to occlude it are not always successful. ${ }^{1}$

The alternative approach we describe does not address the leak directly, but relies on eliminating the conditions that encourage a leak to develop in the first place, and to persist once it has started. We suggest, therefore, that tackling cranial venous outflow obstruction in cases of spontaneous intracranial hypotension sometimes goes closer to the root cause of the condition than a direct attack on the site of leakage. Along with other workers, we have identified the $\mathrm{C} 1$ level in the neck as an area where the jugular veins seem particularly vulnerable to compression and have begun to develop strategies to deal with it. ${ }^{12,18,19,26-28}$ There are likely to be instances where obstruction is at other levels or at multiple sites. ${ }^{29,30}$ There are likely to be cases where relieving venous obstruction will not be enough; perhaps, for example, in patients with connective tissue disorders that significantly weaken the dural membrane. These patients might need a combined approach in which procedures to optimize cerebral venous drainage would be the precursor to a successful and lasting repair of the dural defect.

\section{Funding}

None.

\section{Conflict of Interest}

None declared.

\section{References}

1 Mokri B. Spontaneous low pressure, low CSF volume headaches: spontaneous CSF leaks. Headache 2013;53(07):1034-1053

2 Schievink WI, Maya MM, Jean-Pierre S, Nuño M, Prasad RS, Moser FG. A classification system of spontaneous spinal CSF leaks. Neurology 2016;87(07):673-679

3 Schievink WI, Deline CR. Headache secondary to intracranial hypotension. Curr Pain Headache Rep 2014;18(11):457

4 Urbach H. Intracranial hypotension: clinical presentation, imaging findings, and imaging-guided therapy. Curr Opin Neurol 2014; 27(04):414-424

5 Kumar N, Diehn FE, Carr CM, et al. Spinal CSF venous fistula: a treatable etiology for CSF leaks in craniospinal hypovolemia. Neurology 2016;86(24):2310-2312

6 Mokri B. Intracranial hypertension after treatment of spontaneous cerebrospinal fluid leaks. Mayo Clin Proc 2002;77(11): 1241-1246

7 Schlosser RJ, Woodworth BA, Wilensky EM, Grady MS, Bolger WE. Spontaneous cerebrospinal fluid leaks: a variant of benign intra- cranial hypertension. Ann Otol Rhinol Laryngol 2006;115(07): 495-500

8 Pérez MA, Bialer OY, Bruce BB, Newman NJ, Biousse V. Primary spontaneous cerebrospinal fluid leaks and idiopathic intracranial hypertension. J Neuroophthalmol 2013;33(04):330-337

9 Woodworth BA, Prince A, Chiu AG, et al. Spontaneous CSF leaks: a paradigm for definitive repair and management of intracranial hypertension. Otolaryngol Head Neck Surg 2008;138(06):715-720

10 Owler BK, Allan R, Parker G, Besser M. Pseudotumour cerebri, CSF rhinorrhoea and the role of venous sinus stenting in treatment. $\mathrm{Br}$ J Neurosurg 2003;17(01):79-83

11 King JO, Mitchell PJ, Thomson KR, Tress BM. Manometry combined with cervical puncture in idiopathic intracranial hypertension. Neurology 2002;58(01):26-30

12 Higgins N, Trivedi R, Greenwood R, Pickard J. Brain slump caused by jugular venous stenoses treated by stenting: a hypothesis to link spontaneous intracranial hypotension with idiopathic intracranial hypertension. J Neurol Surg Rep 2015;76(01):e188-e193

13 Higgins JN, Macfarlane R, Axon PR, et al. Headache, cerebrospinal fluid leaks, and pseudomeningoceles after resection of vestibular schwannomas: efficacy of venous sinus stenting suggests cranial venous outflow compromise as a unifying pathophysiological mechanism. J Neurol Surg B Skull Base 2019;80(06):640-647

14 Ray BS, Dunbar HS. Thrombosis of the dural venous sinuses as a cause of pseudotumor cerebri. Ann Surg 1951;134(03):376-386

15 King JO, Mitchell PJ, Thomson KR, Tress BM. Cerebral venography and manometry in idiopathic intracranial hypertension. Neurology 1995;45(12):2224-2228

16 Karahalios DG, Rekate HL, Khayata MH, Apostolides PJ. Elevated intracranial venous pressure as a universal mechanism in pseudotumor cerebri of varying etiologies. Neurology 1996;46(01):198-202

17 Higgins N, Pickard J, Lever A. What do lumbar puncture and jugular venoplasty say about a connection between chronic fatigue syndrome and idiopathic intracranial hypertension? EJMINT Original Article 2014;2014:1448000223

18 Dashti SR, Nakaji P, Hu YC, et al. Styloidogenic jugular venous compression syndrome: diagnosis and treatment: case report. Neurosurgery 2012;70(03):E795-E799

19 Higgins JN, Garnett MR, Pickard JD, Axon PR. An evaluation of styloidectomy as an adjunct or alternative to jugular stenting in idiopathic intracranial hypertension and disturbances of cranial venous outflow. J Neurol Surg B Skull Base 2017;78(02):158-163

20 Zhou D, Ding JY, Ya JY, et al. Understanding jugular venous outflow disturbance. CNS Neurosci Ther 2018;24(06):473-482

21 Chazen JL, Talbott JF, Lantos JE, Dillon WP. MR myelography for identification of spinal CSF leak in spontaneous intracranial hypotension. AJNR Am J Neuroradiol 2014;35(10):2007-2012

22 Akbar JJ, Luetmer PH, Schwartz KM, Hunt CH, Diehn FE, Eckel LJ. The role of MR myelography with intrathecal gadolinium in localization of spinal CSF leaks in patients with spontaneous intracranial hypotension. AJNR Am J Neuroradiol 2012;33(03):535-540

23 Hoxworth JM, Trentman TL, Kotsenas AL, Thielen KR, Nelson KD, Dodick DW. The role of digital subtraction myelography in the diagnosis and localization of spontaneous spinal CSF leaks. AJR Am J Roentgenol 2012;199(03):649-653

24 Schievink WI, Maya MM, Moser FG. Digital subtraction myelography in the investigation of post-dural puncture headache in 27 patients: technical note. J Neurosurg Spine 2017;26(06):760-764

25 Luetmer PH, Mokri B. Dynamic CT myelography: a technique for localizing high-flow spinal cerebrospinal fluid leaks. AJNR Am J Neuroradiol 2003;24(08):1711-1714

26 Zhang X, Li C, Wang Q. Stent placement for treatment of internal jugular vein stenosis: report of 3 cases. Int J Clin Exp Med 2017;10 (09):13881-13887

27 Zhou D, Meng R, Zhang X, et al. Intracranial hypertension induced by internal jugular vein stenosis can be resolved by stenting. Eur J Neurol 2018;25(02):365-e13 
28 Li M, Sun Y, Chan CC, Fan C, Ji X, Meng R. Internal jugular vein stenosis associated with elongated styloid process: five case reports and literature review. BMC Neurol 2019;19(01):112

29 Michel P, Angelillo-Scherrer A, Maeder P, Binaghi S, Meyer IA, Correia P. Stenting as a treatment for exercise-induced intracra- nial hypertension from bilateral jugular vein obstruction. Neurol Clin Pract 2016;6(02):e10-e13

30 Brinjikji W, Graffeo CS, Perry A, et al. Moving target: transient rotsational stenosis precipitating jugular bow hunter's syndrome. J Neurointerv Surg 2017;9(07):e28 